\title{
EDITORIAL
}

\section{A new era for the Journal of Endocrinology and Journal of Molecular Endocrinology}

\author{
Adrian J L Clark ${ }^{1}$ and Anna Spada ${ }^{2}$ \\ ${ }^{1}$ Editor-in-Chief, Journal of Endocrinology and ${ }^{2}$ Editor-in-Chief, Journal of Molecular Endocrinology \\ (Correspondence should be addressed to the Editorial office; Email: editorial@endocrinology.org)
}

Journal of Endocrinology (2012) 213, 207-208

The Journal of Endocrinology (JOE) was founded seventy-three years ago as a vehicle for publishing research in the endocrine sciences. Over the ensuing years the journal proved a vital forum to report the major expansion in endocrinology over this period including a multitude of highly cited articles describing new assays, new hormones and new concepts in endocrinology. However, during the 1970s a technological explosion began with the development of recombinant DNA techniques and DNA sequencing, followed a decade later by invention of the PCR. Understanding of endocrine mechanisms was one of the earliest sectors to benefit from these new developments, and this prompted the founding of a new sister journal for JOE, the Journal of Molecular Endocrinology (JME). This journal development has been an outstanding success - a situation that continues to this day.

The molecular biological revolution that began in the seventies and eighties has not of course spawned an independent discipline of molecular endocrinology. Rather, this technology has over the years become inherent in a multitude of aspects of endocrine science, to the extent that much of the work now published by JOE includes molecular biological methods. As a consequence the subject areas covered by the two journals has become blurred, with authors often uncertain as to which is the preferential journal for publishing their work.

Recognizing this issue, the Publications Committee of the Society for Endocrinology commissioned a wide-ranging and independent in-depth review of its journal portfolio and its place in the universe of publication in endocrinology and metabolism. One of the conclusions of this exercise was that the remit of these two journals was indeed unclear and that many papers would be equally 'at home' in the sister journal. In an attempt to address this a new journal strategy has evolved and in the remainder of this article we outline the key changes that will result.

1. A single joint editorial board. The two journals will be served by a single editorial board structure with one Editor-in-Chief and a Deputy Editor, joint senior editorial board and editorial board. These structures have proved highly effective over the last decade, and a new tier of Associate Editors will be introduced (see below). While manuscripts would still be submitted to one or the other journal, the board would have the opportunity to suggest that manuscripts may be more suitable for the other journal if appropriate. A preliminary scoping exercise examining all manuscripts published over a twelve-month period suggested that about $10 \%$ of papers may be more suitable for the other journal.

2. Associate Editorial tier. The journals hope to maintain and expand their global reach and significance. In order to assist in the development of this area we will establish a new editorial tier of a small number of senior endocrinologists with extensive experience in publishing and academia. These Associate Editors will provide an invaluable source of advice for the development of the journals at both an international and regional level.

3. More precisely defined remit. In conjunction with the editorial board changes outlined earlier, the remit of the two journals has been more clearly defined as follows:

- Journal of Endocrinology - Focus on endocrine physiology and metabolism, including hormone secretion, hormone action and biological effects. The journal will consider basic and translational studies at the cell, tissue and whole organism level.

- Journal of Molecular Endocrinology - Focus on molecular and cellular mechanisms in endocrinology, including

This editorial has been simultaneously published in the Journal of Endocrinology (DOI: 10.1530/JOE-12-0135) and the Journal of Molecular Endocrinology (DOI: 10.1530/JME-12-0064). 
gene regulation, cell biology and signalling. The journal considers basic and pathophysiological studies at the molecular and cellular level.

In summary, we believe that these changes will hold substantial benefit for readers, authors and members of the
Society for Endocrinology and the European Society for Endocrinology. Both journals will continue to publish high quality, expertly peer-reviewed research in a highly timely fashion and to provide a small number of the state-of-the-art reviews of developments in the subject. It is intended that the new structures will come into existence by the end of this year. 